\title{
Textual Conventions
}

In writing for a scholarly but not necessarily a specialist audience, I have endeavored to provide as much technical detail about the primary texts as is necessary without obscuring the general trajectory of my main arguments. The information provided here summarizes the conventions followed in the book.

Unless otherwise noted, translations from the Hebrew Bible and New Testament are based on the NRSV. Where I modify a translation, I provide the NRSV rendering in a footnote.

In texts where the versification between the NRSV and Masoretic Text differ, I use the MT.

I include Hebrew words and phrases in parentheses that are pertinent to the discussion and include diacritical marks only when they are relevant to my argument.

I use "OG" (short for Old Greek) to refer to the ancient Jewish translations of the texts of the Hebrew Bible into Greek (sometimes referred to as the Septuagint or LXX).

For translations of the Dead Sea Scrolls and other Second Temple Jewish literature, I provide citation information at the first occurrence. Hebrew characters that appear within brackets are missing from the document. Those appearing under a small circle are damaged. Both are reconstructed in the cited sources.

Finally, throughout this book I render the tetragrammaton in English using the traditional "the LORD." In Hebrew, I use ['ה]. 
